Case report

\title{
Mesentery root: a rare location of Castleman's disease
}

\author{
Gabriela Maria Aniței ${ }^{\star 1,2}$, Nicolae Șerban loanid ${ }^{2}$, Ana Maria Patrașcu ${ }^{3}$, Gica Ciprian \\ Crețu ${ }^{4}$, Viorel Scripcariu ${ }^{1,2}$
}

1"Grigore T. Popa" University of Medicine and Pharmacy, lasi, Romania; ${ }^{2} 1^{\text {st }}$ Surgical Oncology Clinic, Regional Institute of Oncology, lasi, Romania; ${ }^{3}$ Pathology Department, Regional Institute of Oncology, lasi, Romania; ${ }^{4}$ Radiology Department, Regional Institute of Oncology, lasi, Romania

\begin{abstract}
Castleman's disease $(C D)$ is a rare disorder that involves the lymphoid system and can be uni- or multicentric. While it can arise in any organ that contains lymphoid tissue, most commonly is observed in the mediastinum. Abdominal localizations come second, more often in the retroperitoneum. We report the case of a 49-year-old woman presenting with biliary type dyspepsia and early post-prandial satiety whose imaging evaluations revealed uncomplicated cholelithiasis and a $3.5 \mathrm{~cm}$ nodule situated at the root of the mesentery. The patient was treated with surgery - cholecystectomy and en bloc resection of the mesenteric root mass. Histology exam of the surgical specimen concluded for a hyaline-vascular type $C D$, also confirming the negative resection margins of the tumor. Postoperatively, the patient's evolution was favorable, with discharge at the $5^{\text {th }}$ postoperative day. No adjuvant treatment was necessary. The hematology evaluation excluded any underlying lymphoproliferative disorder or chronic viral infection. One year after surgery, the patient has no recurrence.
\end{abstract}

Keywords: Castleman's disease; lymphoproliferative disorder; mesentery root

\section{Introduction}

Castleman's disease (CD) is a rare lymphoproliferative disorder. Its prevalence has been estimated recently to be 21 to 25 cases per million person-years [1], and thus qualifying it as a rare disease.

The first reported case was published in 1954 by the pathologist Dr. Benjamin Castleman [2]. The disease can be unicentric or multicentric, in the latter it may be associated with human herpes virus 8 (HHV-8) or human immunodeficiency virus (HIV) infection.

Received: October 2018; Accepted after review: December 2018; Published: December 2018.

${ }^{*}$ Corresponding author: Gabriela Maria Anitei, $1^{\text {st }}$ Surgical Oncology Clinic, Regional Institute of Oncology, 35 G-ral Berthelot Str, lasi, Romania.

Email:dr.mgabriela@gmail.com
Four subtypes of CD are described: (1) hyaline vascular - usually unicentric, (2) plasma cell rich - more frequently multicentric (3) HHV-8 associated CD - mainly multicentric in the immunocompromised and multicentric not otherwise specified [3].

Although $C D$ can involve any area containing lymphoid tissue, it is mainly encountered in the mediastinum (70\%); the abdominal localizations come second (15\%), of which the retroperitoneal ones are more prevalent. As of 2014 , only about a thousand cases of CD were reported in the literature [4].

\section{Case report}

A 49-year old woman without previous medical history was referred to our service for biliary type dyspepsia and early post-prandial satiety, with an ultrasound description of gallstones and a nodule in the inferior part of 
the duodenal-jejunal junction. Subsequently, she underwent abdominal CT-scan with intravenous contrast showing uncomplicated cholelithiasis and a $3.5 \mathrm{~cm}$ nodule located at the root of the mesentery, which enhanced after contrast, with a pedicle containing vessels stemming from the superior mesenteric vessels (Figure 1).

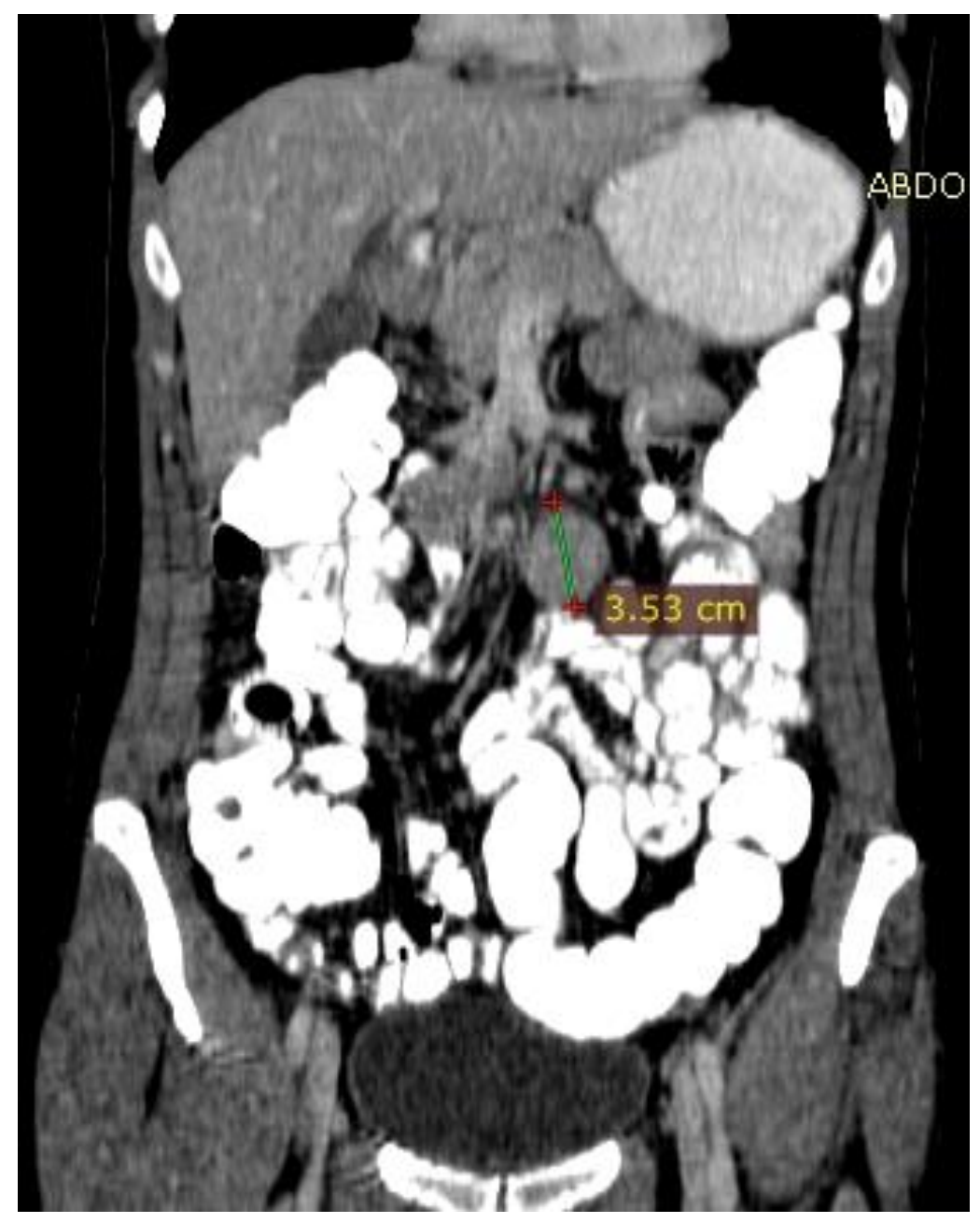

Fig. 1. Venous-phase CT-scan in coronal view shows a homogenously enhanced nodule, in contact with the fourth duodenum, mesenteric root, first jejunal loops (without invasion); the vascular pedicle of the tumor came from the superior mesenteric vessels.

CT-interpretation could not clearly differentiate a neuroendocrine tumor from schwannoma, leiomyoma, unicentric $C D$ or other tumor types. Contrast abdominal MRI revealed a left para-aortic nodule, 36/30/32 $\mathrm{mm}$ in size, neighboring the caudal end of the renal arteries, probably of mesenteric origin (Figure 2).

The patient was then scheduled for surgery a couple of weeks later. 


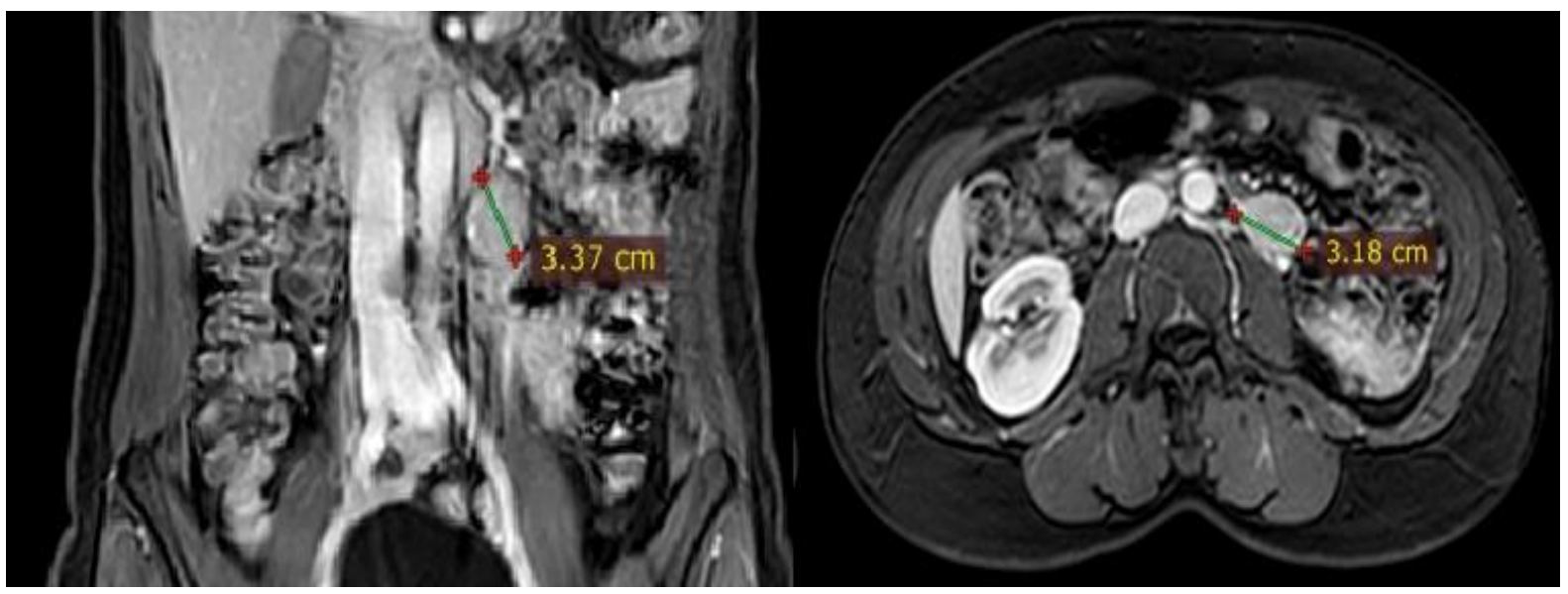

Fig. 2. T1-weighted abdominal MRI, after contrast. Left: coronal view MRI shows the left para-aortic mass. Right: axial view of the mass. Both images indicate a fatty separation plane between the nodule and the abdominal aorta.

We decided for an upper midline laparotomy approach; the gallbladder walls were thin with no inflammatory signs while at the root of the mesentery, we revealed a round-shaped tumor, $4 \mathrm{~cm}$ in diameter, with a well-defined capsule and of firm consistency, in close contact with the fourth portion of the duodenum (Figure 3).



Fig. 3. Intraoperative view. The head of the patient is at the top of the image. View before beginning of tumor dissection (circle). We can observe its contact with the 4th duodenum (arrow).

"En bloc" excision of the mesenteric root tumor and a bipolar cholecystectomy were performed (Figure 4). Onwards, the evolution of the patient was simple with a symptomatic treatment and was discharged at the $5^{\text {th }}$ postoperative day. 


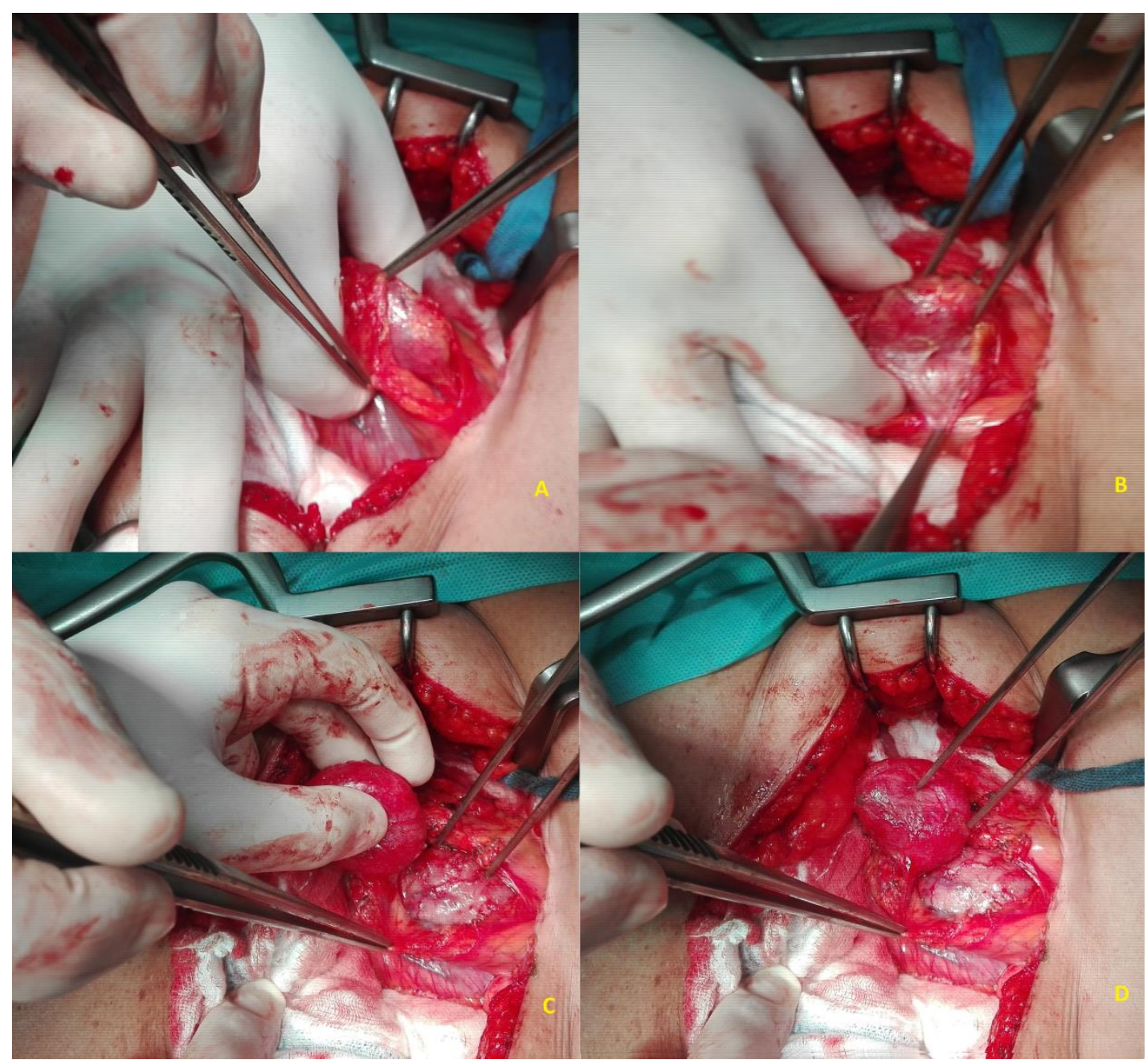

Fig. 4. A - C: progressive dissection of the tumor from the surrounding tissues; D - Vascular pedicle of the tumor arising from the superior mesenteric vessels.

As far as histology exam was concerned, macroscopic examination described a nodular tumor of $3.5 / 3 / 1.7 \mathrm{~cm}$; seriate sections show a compact, brown-yellow micronodular structure. Microscopy revealed a lymph node with a relatively preserved general structure, distorted by multiple lymphoid follicles placed in cortical and medullar regions. The lymph nodes presented small germinal centers (some follicles having two germinal centers), lymphocyte depletion, with a predominance of dendritic cells and with focal hyaline deposits. The mantle area of the follicles was well represented, with lymphocytes disposed concentrically. Small arterioles were observed, with hyaline walls radially penetrating the germinal centers. Interfollicular areas were composed of blood vessels with high endothelium, some with hyaline walls, small lymphocytes and rare eosinophils. Thus, the histology exam concluded for a hyalinevascular type Castleman's disease (Figure 5).

Post-surgery follow-up at 3 months, showed no recurrence at abdominal ultrasound and immunology tests for HIV, hepatitis $B$ and hepatitis $C$ infection were negative. CT-scan at 6 and 12 months after surgery did not reveal any recurrence or adenopathy. 

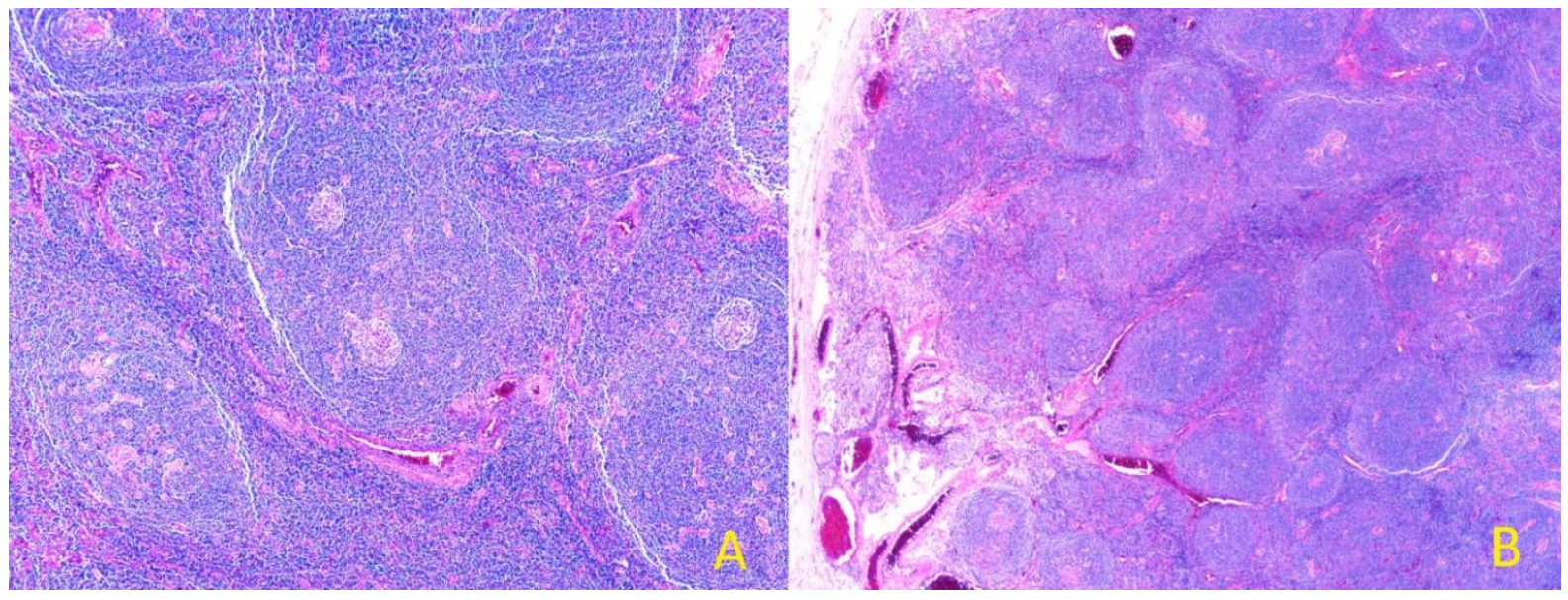

Fig. 5. A - Double germinal center (HE, $x 100)$. B - Lymphoid follicles in the mantle area showing a tendency towards concentric disposition of lymphocytes (HE, x40).

\section{Discussions}

A lymphoproliferative disorder [5], also termed by many as "lymph node hamartoma", is usually asymptomatic in unicentric hyalinevascular subtypes. The multicentric plasmocytic subtypes may present with the "B" symptoms encountered in lymphomas with polyclonal hyperglobulinemia, the pathophysiology of $C D$ residing in an excessive proliferation of $B$ lymphocytes and plasma cells) [6]. Our patient did not complain of anything but digestive symptoms and the protein electrophoresis and immuneelectrophoresis were completely normal, falling in line with the characteristics of the hyaline-vascular type, which, as described, turned out to be on histological exam.

The treatment for unicentric disease is usually surgical excision alone, while for the multicentric disease, the options may be a combination of chemotherapy, radiotherapy, biological therapy, antiviral agents, corticosteroids, etc. [7].

For the unicentric type, when complete surgical resection is not possible, one can attempt chemotherapy or radiation therapy which show promising results, albeit in a very limited number of reported cases [8]. Bandera et al [9] reported a case of CD involving the major vessels in the mediastinum treated with biological neoadjuvant therapy (Rituximab), allowing for a less extensive and marginnegative surgical resection. Our patient did not show any signs of multiple nodal involvements on preoperative and postoperative imaging and the tumor was removed in its entirety, therefore she did not receive any systemic treatment. Even though many consider today surgery as the treatment of choice for unicentric CD [10], one may argue that as possibilities for preoperative diagnosis increase, biological therapy refines and considering the benign nature of the disease and its good response to systemic therapy, at least some of the patients will be able to control the disease through medication, thus sparing them of operative procedures, sometimes extensive, e.g. pancreatoduodenectomy [11].

For unicentric CD of hyaline-vascular type, CT-scan characteristics are of an enlarged lymph node, with intense and homogeneous contrast enhancement, with distinguishable feeding vessels [12], features present in this case report.

Vassos et al. [13] reported an obstructive mesenteric root hyaline-vascular CD, that necessitated mass excision with segmental jejunal resection through open abdominal approach. Another case of CD encountered at the mesenteric root was communicated by Papaziogas et al. [14]. The tumor was ablated together with a jejunal loop and the mesentery. A pediatric case (an 11-year-old male patient) of $C D$ with the same location was published by Hung et al [15]. The patient presented 
important "B" symptoms, all remitting after surgery.

Another case with the same location, a hyaline-vascular $C D$, was reported by Ma et al [16] who performed surgical resection of the tumor without small bowel resection.

In all of the aforementioned cases, as well as in ours, a midline laparotomy approach was used. To our knowledge, this is only the fifth reported mesentery root CD.

\section{Conclusion}

The current case report is a particular one, given its diagnostic challenge and the fact that this patient presented with a rare location for

\section{References}

1. Munshi $N$, Mehra $M$, van de Velde $H$, Desai $A$, Potluri $\mathrm{R}$, Vermeulen $\mathrm{J}$. Use of a claims database to characterize and estimate the incidence rate for Castleman disease. Leuk Lymphoma 2015; 56(5):1252-1260.

2. Cabot RC, Castleman B, Towne VW. Case 40351. N Engl J Med 1954; 251(10):396-400.

3. Cronin DMP, Warnke RA. Castleman disease: an update on classification and the spectrum of associated lesions. Adv Anat Pathol 2009; 16(4):236-246.

4. Aguilar-Rodriguez R, Milea S-L, Demirci I, et al. Localized retroperitoneal Castleman's disease: a case report and review of the literature. $J$ Med Case Rep 2014; 8(1):93.

5. Greco LG, Tedeschi M, Stasolla S, Gentile A, Gentile A, Piscitelli D. Abdominal nodal localization of Castleman's disease: Report of a case. Int J Surg 2010; 8(8):620-622.

6. Saeed-Abdul-Rahman I, Al-Amri AM. Castleman disease. Korean J Hematol 2012; 47(3):163-177.

7. El-Osta HE, Kurzrock R. Castleman's disease: from basic mechanisms to molecular therapeutics. Oncologist 2011; 16(4):497-511.

8. Chan K-L, Lade S, Prince HM, Harrison SJ. Update and new approaches in the treatment of Castleman disease. J Blood Med 2016; 7:145-158.

9. Bandera B, Ainsworth C, Shikle J, Rupard E, Roach M. Treatment of unicentric Castleman disease with neoadjuvant rituximab. Chest 2010; 138(5):1239-1241. an already very rare tumor, with no specific symptoms and no preoperative histological diagnosis. Margin-negative excision is the treatment of choice in unicentric Castleman's disease.

\section{Consent}

Written informed consent was obtained from the patient for publication of this case report and accompanying images. A copy of the written consent is available for review by the Editor-in-Chief of this journal.

\section{Competing interests}

The authors declare that they have no competing interests.

10. Talat N, Belgaumkar AP, Schulte K-M. Surgery in Castleman's Disease. Ann Surg 2012; 255(4):677-684.

11. Wang $H$, Wieczorek $R L$, Zenilman $M E$, DesotoLapaix F, Ghosh BC, Bowne WB. Castleman's disease in the head of the pancreas: report of a rare clinical entity and current perspective on diagnosis, treatment, and outcome. World $\mathrm{J}$ Surg Oncol 2007; 5:133.

12. Bonekamp D, Horton KM, Hruban RH, Fishman EK. Castleman disease: the great mimic. Radio Graphics 2011; 31(6):1793-1807.

13. Vassos N, Raptis D, Lell $M$, et al. Intraabdominal localized hyaline-vascular Castleman disease: imaging characteristics and management of a rare condition. Arch Med Sci 2016; 12(1):227-232.

14. Papaziogas B, Chatzimavroudis G, Koutelidakis I, Grigoriou M, Atmatzidis K. A rare form of isolated mesenteric Castleman's disease presenting as an abdominal mass (isolated mesenteric Castleman's disease). J Gastrointestin Liver Dis 2006; 15(2):171-174.

15. Hung IJ, Kuo TT, Lin JN. New observations in a child with angiofollicular lymph node hyperplasia (Castleman's disease) originated from the mesenteric root. $A m \checkmark$ Pediatr Hematol Oncol 1992; 14(3):255-260.

16. $\mathrm{Ma} H$, Jiang $M$, Xiao $W$. A rare stroma-rich variant of hyaline-vascular Castleman's disease associated with calcifying fibrous pseudotumor. Int J Clin Exp Pathol 2015; 8(3):3362-3364. 